\title{
Métodos Geofísicos Aplicados a Coberturas Lateríticas com Feições Pseudocársticas na Mina de Ferro N4E, Carajás
}

\author{
Marcelo Roberto Barbosa (Vale SA), Rafael Guimarães de Paula (Vale SA), Marco Antonio Braga (UFRJ), luri Viana Brandi \\ (Vale SA), Cibele Clauver (UNIBH), Juliano Matos (NEOGEO), Leonardo Santana de Oliveira Dias (COFFEY)
}

Copyright 2016, SBGf - Sociedade Brasileira de Geofísica

Este texto foi preparado para a apresentação no VII Simpósio Brasileiro de Geofísica, Ouro Preto, 25 a 27 de outubro de 2016. Seu conteúdo foi revisado pelo Comitê Técnico do VII SimBGf, mas não necessariamente representa a opinião da SBGf ou de seus associados. É proibida a reprodução total ou parcial deste material para propósitos comerciais sem prévia autorização da SBGf.

\section{Resumo}

Foi testada a aplicabilidade de dois métodos de geofísica rasa (Ground Penetrating Radar - GPR e Sondagem Elétrica Vertical Multi-Eletrodos - SEVME) em coberturas lateríticas com feições pseudocársticas na mina de ferro N4E em Carajás, especificamente sobre cavidades naturais subterrâneas. $\mathrm{O}$ estudo das cavidades em áreas de mineração é uma exigência de licenciamento ambiental da legislação federal vigente. O objetivo dos estudos geofísicos foi melhorar a qualidade do mapeamento litoestrututral de cavidades, principalmente nas porções entre a superfície do terreno e seu teto. Este trabalho apresenta os resultados dos testes sobre diferentes arranjos, frequências e tratamento dos dados geofísicos. Foi possível definir profundidades, planos de descontinuidades e domínios estruturais contribuindo fortemente para a interpretação das questões de estabilidade estrutural das cavidades.

\section{Introdução}

Os platôs da região dos Carajás constituem um grande contraste geomorfológico no sudeste do estado do Pará, representados por um conjunto de serras com cotas topográficas que variam de $500-850 \mathrm{~m}$, cercadas por grandes áreas arrasadas cujas cotas variam de 250-350 $\mathrm{m}$, possuindo diferenças de altura atingindo até $500 \mathrm{~m}$. Estes platôs foram formados entre as idades do Cretáceo e Terciário Superior e encontram-se alinhados na direção estrutural regional W-NW e E-SE.

Geologicamente, a região é dominada por uma sequência de rochas vulcanossedimentares de idade arqueana do Grupo Grão Pará (Macambira, 2003), que hospeda uma grande província mineral, incluindo as maiores reservas de minério de ferro no mundo, exploradas pela empresa Vale SA. O topo dos platôs, onde estão localizadas as minas de ferro, é sustentado por uma cobertura laterítica resistente aos processos erosivos que desenvolve feições pseudocársticas, destacando-se por apresentar uma expressiva ocorrência de cavidades naturais subterrâneas em suas bordas.
Atualmente, a legislação ambiental federal exige a preservação de cavidades, solicitando ao empreendedor manter uma distância de $250 \mathrm{~m}$ de cada cavidade, onde não pode haver qualquer tipo de intervenção humana até que se demonstre através de estudos técnico-científicos (físicos e biológicos), que o avanço da mina não irá causar qualquer tipo de impacto irreversível à cavidade e, nesses casos, uma autorização pode ser emitida pelos órgãos ambientais. Esta distância de proteção de cavidades em 250m afeta substancialmente o planejamento da lavra, tornando-o complexo, improdutivo e caro, chegando a imobilizar reservas expressivas de minério.

Para atender a legislação e, em especial, entender o comportamento do meio físico em ambientes com a presença de cavidades, estudos geológicos, hidrogeológicos, sismográficos e geotécnicos vem sendo executados pela Vale. Especificamente no que tange a estabilidade estrutural das cavidades, diversos tipos de mapeamentos e monitoramentos estão em execução, porém métodos indiretos como a geofísica estão mostrando bons resultados para enxergar aspectos estruturais importantes do maciço, especialmente no trecho entre a superfície do terreno e o teto das cavidades.

Este trabalho vai abordar os resultados de testes geofísicos pelos métodos eletromagnéticos, GPR, e elétrico, SEVME, executados em terrenos lateríticos sobre a cavidade N4E-0026 e seu interior, nas mesmas linhas topográficas transversais e longitudinais ao eixo principal da cavidade, na mina de ferro N4E em Carajás (Figura 1). 


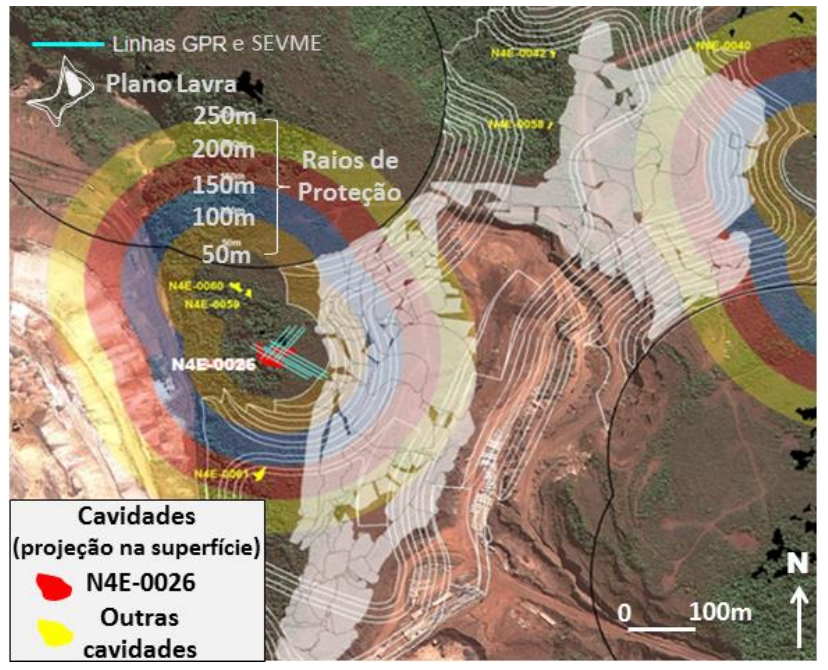

Figura 1: Localização das linhas GPR e SEVME sobre a cavidade N4E-0026 na Mina N4E.

\section{Metodologia}

\section{Ground Penetrating Radar - GPR}

O GPR ou Radar de Penetração no Solo é um método geofísico não invasivo e que utiliza ondas eletromagnéticas com frequências entre 10 a $2.500 \mathrm{MHz}$. Consiste na emissão e propagação de ondas eletromagnéticas, em um meio físico, com a posterior recepção dos sinais refletidos por descontinuidades desse meio (refletores), podendo ser interpretados, formas de corpos em subsuperfície e descontinuidades geológicas como foliações, falhas, fraturas, acamamentos e mergulhos de camadas.

O sistema do GPR pode ser resumido por uma fonte geradora de pulsos elétricos de alta frequência, uma antena transmissora, uma antena receptora e uma unidade de armazenamento de dados. Foram realizados testes com antenas de frequências $80 \mathrm{MHz}$ Multi Low Frequence (MLF), $100 \mathrm{MHz}, 200 \mathrm{MHz}$ e $400 \mathrm{MHz}$ para definição das profundidades em coberturas lateríticas e sua relação com a resolução do imageamento dos dados geofísicos. No total foram realizados $3.022 \mathrm{~m}$ de seções geofísicas pelo método GPR.

A Figura 2 mostra a equipe em caminhamento ao longo de uma seção com antena GPR de $80 \mathrm{MHz}$.

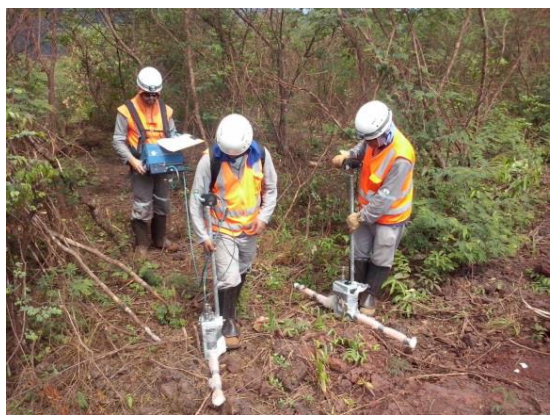

Figura 2: Levantamento Seção GPR com antena $80 \mathrm{MHz}$.

\section{Sondagem Elétrica Vertical Multi-Eletrodos - SEVME}

A eletrorresistividade é um método geofísico baseado na determinação da resistividade elétrica dos materiais, dividido em duas técnicas de levantamentos de campo, Sondagem Elétrica Vertical (SEV) e Sondagem Elétrica Vertical Multi-Eletrodos (SEVME). Este trabalho utilizou a técnica de SEVME uma vez que o alvo de interesse foi a variação lateral da resistividade. Esse método emprega uma corrente elétrica direta baseada na emissão artificial introduzida no terreno através de dois eletrodos de corrente (denominados A e B) com o objetivo de medir 0 potencial gerado em outros dois eletrodos de potencial (denominados $\mathrm{M}$ e $\mathrm{N}$ ) nas proximidades do fluxo de corrente. Com isso, é possível identificar regiões em subsuperfície como solos e rochas que apresentam maior ou menor resistividade principalmente pela composição mineralógica, concentração de argilo-minerais, porosidade, grau de compactação, teor em água, natureza dos sais dissolvidos entre outros. Os eletrodos foram cravados no solo por percussão a martelo ou por rosqueamento para melhorar a conexão elétrica.

A Figura 3 mostra a seção SEVME sobre a cavidade N4E-0026 em terreno laterítico.

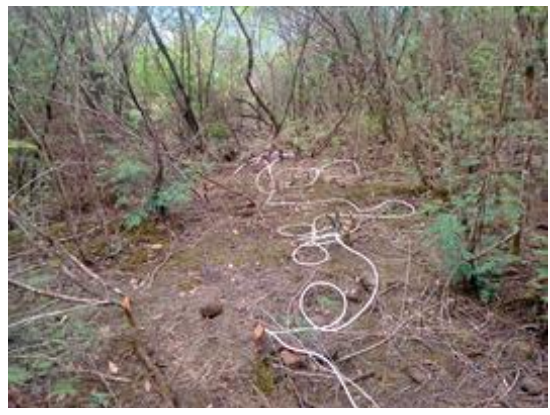

Figura 3: Levantamento de Seção SEVME sobre a cavidade N4E-0026 em terreno laterítico.

Foram realizados testes geofísicos para a escolha do melhor arranjo de eletrodos a ser utilizado para as seções. Foram efetuados os arranjos Dipolo-Dipolo, Gradiente e Schlumberger, sendo o que apresentou a melhor relação sinal versus ruído foi o Arranjo DipoloDipolo. No total foram realizados $1.524 \mathrm{~m}$ pelo método elétrico SEVME.

\section{Resultados \\ Ground Penetrating Radar - GPR}

As profundidades alcançadas com as diferentes antenas encontram-se na Tabela 1, sendo a maior delas de cerca de $12 \mathrm{~m}$ em $80 \mathrm{MHz}$. Com isso o método mostrou-se apropriado, considerando que a profundidade média para a ocorrência de cavidades na região é de $10 \mathrm{~m}$. 
Tabela 1: Profundidades alcançadas nas seções GPR em terrenos lateríticos sobre a cavidade N4E-0026 na mina N4E.

\begin{tabular}{cc}
\hline Antena GPR & $\begin{array}{c}\text { Profundidade de } \\
\text { alcance }(\mathbf{m})\end{array}$ \\
\hline $80 \mathrm{MHz}$ & 12 \\
$100 \mathrm{MHz}$ & 10 \\
$200 \mathrm{MHz}$ & 8 \\
$400 \mathrm{MHz}$ & 2 \\
\hline
\end{tabular}

As seções apresentaram boas resoluções e foram apresentadas por meio de uma paleta em tons escuros. O teto da cavidade foi identificado com dificuldade através da presença de hipérboles interpretadas com localização inferida. A análise das seções não permitiu identificar contatos claros entre diferentes litotipos. Em todas as seções, nas diferentes antenas utilizadas, os refletores tendem a ser planos, por vezes com mergulho, relativamente regulares, e moderadamente contínuos a descontínuos. As seções, nas diversas frequências apresentam descontinuidades dos refletores que podem ser associados às descontinuidades e possíveis planos de fraqueza (Figura 4).

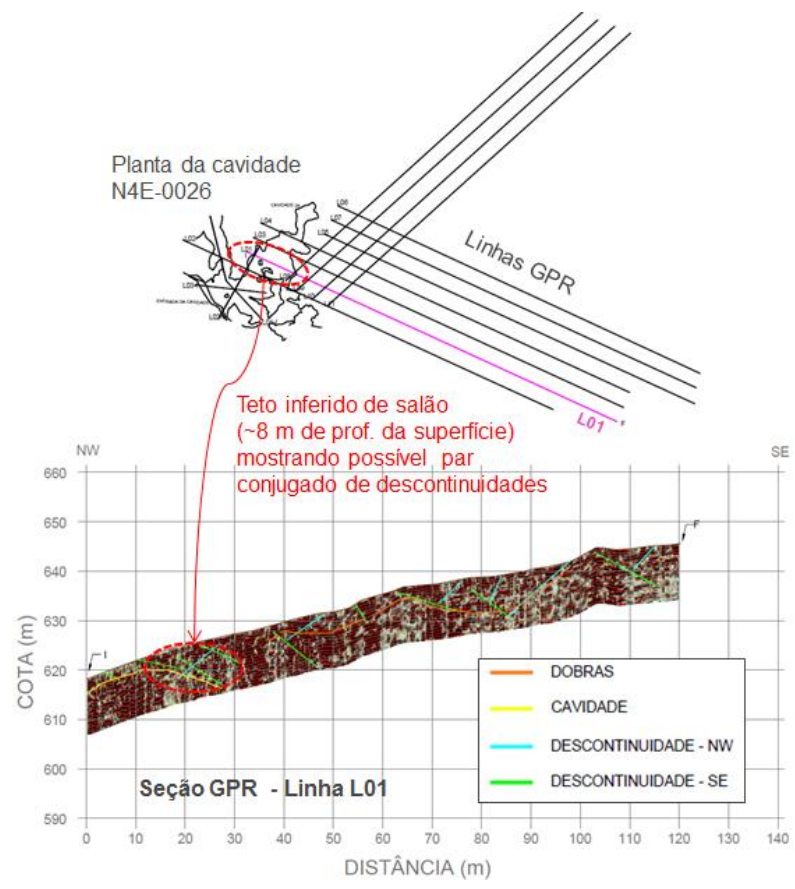

Figura 4: Seção GPR interpretada sobre a cavidade N4E0026 em terreno laterítico. Notar a interpretação de descontinuidades mostrando possíveis pares conjugados, importantes para as questões de estabilidade estrutural.

Os perfis apresentam superfícies que podem indicar dobras, em várias escalas, que podem estar relacionados $\mathrm{Em}$ algumas seções foram identificadas feições anômalas e sem continuidade lateral que podem sugerir planos ou cunhas de fraqueza. Em todas as feições identificadas houve a tentativa de correlação com os resultados para todas as frequências utilizadas. Diversos planos de descontinuidades podem ser detectados em frequências diferentes.

As descontinuidades e/ou planos de fraqueza possuem medidas variadas de mergulho e direção, Através da integração dos diferentes planos de descontinuidade foi possível estabelecer quatro principais direções: NW-SE, NE-SW, E-W e WNW-ESE, plotadas no estereograma da Figura 7. Estas direções correspondem a atitudes no interior e entorno da cavidade N4E-0026 obtidas de mapeamentos geoestruturais.

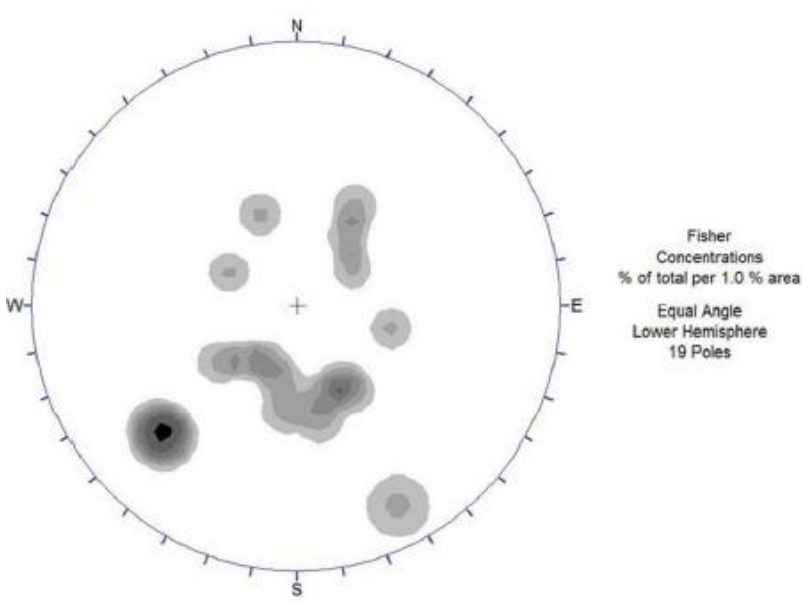

\section{Sondagem Elétrica Vertical Multi-Eletrodos - SEVME}

A profundidade alcançada com o arranjo dipolo-dipolo utilizado foi de cerca de $25 \mathrm{~m}$. Com isso o método também se mostrou apropriado em razão da média de profundidade de $10 \mathrm{~m}$ para as cavidades da região.

O parâmetro geofísico resistividade aparente fornecido pelo método de eletrorresistividade utilizado por meio da técnica de campo caminhamento elétrico ofereceu boa resolução de imageamento permitindo boa interpretação.

As análises das seções geofísicas consideraram as diferenciações nos perfis em virtude da sua magnitude em Zonas de Alta Resistividade aparentes (ZAR), Zonas de Baixa Resistividade aparentes (ZBR) e Zonas de Resistividade Intermediárias (ZIR). Embora os valores que definam cada zona possam variar de acordo com a seção, as mesmas podem ser correlacionadas.

\section{Normalização e Transformação dos Dados}

A normalização consiste em definir o formato lógico adequado para estruturas de dados, com o objetivo de minimizar o espaço utilizado pelos mesmos e garantir a integridade e confiabilidade das informações. No presente trabalho foi proposta a normalização para algumas seções, através de uma média dos valores da cada faixa de resistividade considerando, assim, que os valores normalizados possuam os devidos desvios 
padrões para os valores reais. Desses resultados podemse extrair duas importantes conclusões. Primeiramente, os resultados históricos analisados mostram uma excelente correlação dos dados geofísicos com as interpretações geológicas. Em segundo lugar, os resultados não extrapolam os desvios padrão da cada zona de resistividade.

Portanto, as seções externas à cavidade N4E-0026 tiveram os valores de resistividade aparente normalizados uma vez que a quantidade significativa de dados associados a esta permitiu a extrapolação dos valores a todas as seções sem perda da confiabilidade da interpolação geofísica. Desta forma, o range de resistividade aparente variou uniformemente, sendo a ZAR definida por valores acima de $8.800,0$ ohm.m.

A Figura 5 mostra um exemplo da interpretação de uma seção SEVME sobre a cavidade N4E-0026.

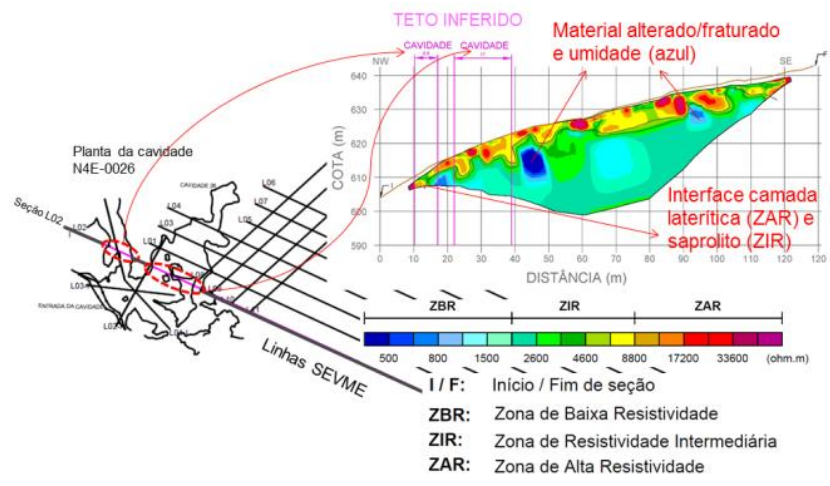

Figura 5: Seção SEVME interpretada sobre a cavidade N4E-0026 em terreno laterítico. Notar a interpretação de materiais (litotipos) diversos em subsuperfície, mostrando possíveis zonas de alteração/fraturamento nas ZBRs (fragilidade estrutural?) e interfaces entre a cobertura laterítica (ZARs) e o saprolito (ZIR).

\section{Discussão e Conclusões}

Em função dos objetivos dos testes geofísicos que buscam melhorar a qualidade do mapeamento litoestrututral de cavidades, principalmente nas porções entre a superfície do terreno e seu teto, os resultados foram considerados positivos e devem ter continuidade para confirmação e aprimoramentos.

A Tabela 2 detalha os principais resultados alcançados.

Tabela 2 Principais resultados alcançados nos testes geofísicos sobre a cavidade N4E-0026 em cobertura laterítica na Mina N4E.

\begin{tabular}{|l|l|}
\hline \multicolumn{1}{|c|}{ GPR } & \multicolumn{1}{c|}{ SEVME } \\
\hline $\begin{array}{l}\text { O arranjo proposto } \\
\text { obteve boa performance }\end{array}$ & $\begin{array}{l}\text { O arranjo proposto obteve boa } \\
\text { performance de execução e }\end{array}$ \\
\hline
\end{tabular}

\begin{tabular}{|c|c|}
\hline $\begin{array}{l}\text { de execução e a leitura } \\
\text { conseguiu identificar } \\
\text { alvos com até } 12 \mathrm{~m} \text { de } \\
\text { profundidade } \\
\text { (antena80MHz). }\end{array}$ & $\begin{array}{l}\text { leitura até } 25 \mathrm{~m} \text { de } \\
\text { profundidade. }\end{array}$ \\
\hline $\begin{array}{l}\text { Consegiu marcar planos } \\
\text { de descontinuidades em } \\
\text { seções 2D que auxiliam } \\
\text { a identificar interseções } \\
\text { de descontinuidades em } \\
\text { cunhas, entre a } \\
\text { superfície do terreno e o } \\
\text { teto da cavidade. }\end{array}$ & $\begin{array}{l}\text { Pode servir de auxílio para } \\
\text { mapear/confirmar aspectos } \\
\text { estruturais entre a superfície } \\
\text { do terreno e o teto das } \\
\text { cavidades com as diferentes } \\
\text { resistividades interpretadas. }\end{array}$ \\
\hline $\begin{array}{l}\text { A análise integrada 3D } \\
\text { das seções GPR } \\
\text { mostrou ser um } \\
\text { importante aliado na } \\
\text { interpretação estrutural, } \\
\text { ressaltando aspectos } \\
\text { relevantes de fragilidade } \\
\text { entre o terreno e o teto } \\
\text { da cavidade. }\end{array}$ & $\begin{array}{l}\text { Em princípio, mostrou boa } \\
\text { diferenciação de resistividade } \\
\text { para perfis lateríticos } \\
\text { (espessura dos estratos e } \\
\text { seus níveis de } \\
\text { compactação/porosidade da } \\
\text { matriz), }\end{array}$ \\
\hline $\begin{array}{l}\text { Os domínios estruturais } \\
\text { mapeados no GPR } \\
\text { confirmam e detalham } \\
\text { as atitudes registradas } \\
\text { do mapeamento. }\end{array}$ & $\begin{array}{l}\text { As seções conseguiram } \\
\text { marcar zonas de baixíssima } \\
\text { resistividade indicando } \\
\text { possível intenso } \\
\text { intemperismo, aspecto } \\
\text { importante na confirmação } \\
\text { das zonas de fragilidade. }\end{array}$ \\
\hline
\end{tabular}

\section{Referências}

Macambira, J.B. 2003. O ambiente deposicional da Formação Carajás e uma proposta de modelo evolutivo para a Bacia Grão Pará: Tese de Doutorado, Instituto de Geociências, Universidade Estadual de Campinas, p. 217. 